\title{
Ni-W-P Catalyzed Growth of Carbon Nanotubes on SiC Whiskers
}

\author{
Dongyan Ding ${ }^{1 *}$, Congqin Ning ${ }^{2}$ and Alan Dozier ${ }^{3}$ \\ ${ }^{1}$ Institute of Microelectronic Materials and Technology, School of Materials Science and Engineering, Shanghai Jiao Tong University, Shanghai 200240, China \\ ${ }^{2}$ State Key Laboratory of High Performance Ceramics and Superfine Microstructure, Shanghai Institute of Ceramics, Chinese Academy of Sciences, \\ Shanghai 200050, China \\ ${ }^{3}$ Electron Microscopy Facility, University of Kentucky, Lexington, KY 40506, USA
}

Received: November 01, 2013; Accepted: December 05, 2013; Published: December 12, 2013

"Corresponding author: Dongyan Ding, Institute of Microelectronic Materials and Technology, School of Materials Science and Engineering, Shanghai Jiao Tong University, Shanghai 200240, China, Tel: +8621 34202741; Fax: +86-21-34202741, E-mail: dyding@sjtu.edu.cn

\begin{abstract}
$\mathrm{Ni}-\mathrm{W}$-P nanoislands deposited on the surface of semiconducting $\mathrm{SiC}$ whiskers were investigated on its role in a catalytic growth of carbon nanotubes during thermal pyrolysis of acetylene. Experimental results indicated that a large quantity of carbon nanotubes formed although complex chemical reactions among the transition metals ( $\mathrm{Ni}$ and $\mathrm{W}), \mathrm{SiC}$ and carbon source had occurred to yield nickel silicides and tungsten carbide (WC). Multi-element catalytic growth of carbon nanostructures was found with the Ni-W-P catalyst. Favorable heterostructures made up of carbon nanotube/ semiconducting $\mathrm{SiC}$ whisker are expected.
\end{abstract}

\section{Introduction}

Transition metals and their alloys are important catalysts for a catalytic growth of carbon nanotubes [1-3]. These catalysts could be prepared on various substrates such as silicon wafer, zeolite, and even carbon nanotube. At elevated temperatures, metallic catalysts tend to aggregate and grow into large catalyst particles, which will be unfavorable for the growth of ultrafine nanostructures. Thus, controlling the surface morphology, size, and distribution of the catalyst particles by using appropriate preparation processes and supporting materials is of great importance [4-6]. To meet such a requirement, electroless plating shows its many advantages such as realizing a simple and flexible deposition of highly dispersed binary or ternary alloy catalysts on various materials $[7,8]$.

Moreover, nanodevices made up of one-dimensional heterojunctions and heterostructures $[9,10]$ are of great interest with rapid development of nanoscale science and technology. $\mathrm{Hu}$ et al. reported a rectifying behavior of CVD heterojunctions between multi-walled carbon nanotubes and $\mathrm{Si}$ nanowires. Zhang et al. used a solid-solid reaction method to fabricate heterostructures made up of single-walled carbon nanotubes and nanorods or particles of silicon carbide and transition metal carbides. To fabricate SiC semiconductor /carbon nanotube heterostructure, we used sub-micrometer-sized SiC whiskers to support Ni-W-P nanoparticles for a catalytic growth of carbon nanotubes. The role of the multi-element catalyst during the pyrolysis reaction was examined.

\section{Experimental Procedure}

$\beta$-SiC whiskers (10-30 $\mu \mathrm{m}$ in length and 0.1-1.0 $\mu \mathrm{m}$ in diameter) were sensitized in a $\mathrm{SnCl}_{2}$ solution and then activated in a $\mathrm{PdCl}_{2}$ solution. $\mathrm{Ni}-4.5 \mathrm{~W}-19.9 \mathrm{P}$ (at \%) (with a high melting point about $1240^{\circ} \mathrm{C}$ ) nanoislands were deposited on the surfaces of the SiC whiskers by electroless plating (Figure 1) [11,12]. A silica plate covered with the $\mathrm{Ni}-\mathrm{W}-\mathrm{P} / \mathrm{SiC}$ powders was put in a quartz tube, which was heated to $700^{\circ} \mathrm{C}$ in Ar atmosphere. Pyrolysis of $\mathrm{C}_{2} \mathrm{H}_{2}$ (20-30 ml/min) was then carried out with $\mathrm{Ar}$ as the dilute gas (at a flow rate of 200-500 ml/min). After 10-60 minutes of reaction, pyrolysis products were collected and then ultrasonically dispersed in absolute alcohol for 5-30 minutes for examination with X-ray diffraction (XRD, Rigaku D/MAX-III) and field emission transmission electron microscope (TEM, JEM 2010F) equipped with energy dispersive spectroscopy (EDS).

\section{Results and Discussion}

The pyrolysis reaction yielded a large quantity of carbon

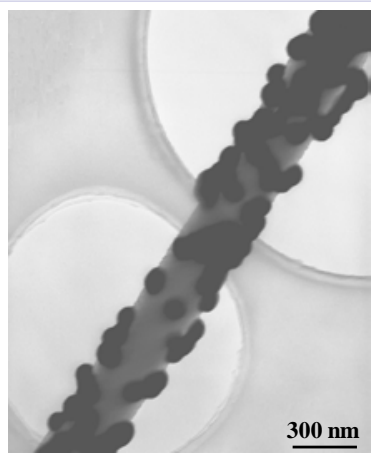

Figure 1: TEM images of Ni-W-P nanoislands deposited on the surface of a $\mathrm{SiC}$ whisker. 
nanotubes with diameters around $40 \mathrm{~nm}$. Quite a few of the carbon nanotubes consisted of highly compartmentalized structures (Figure 2). The carbon nanotubes could be connected to the semiconducting whisker due to short reaction time or incomplete diffusion of the nanostructures away from the whisker (Figure 3). Corresponding HREM observations revealed that the compartmentalized structures were composed of short graphene layers, which formed a certain degree of alignment along both the longitudinal direction of the nanotubes and the stacking cones in the center of the carbon nanotubes. TEM observations of the multiple kinks and fracture of the nanotubes (Figure 2) revealed that, during the ultrasonic vibration of the carbon nanotubes, a severe deformation or fracture of the carbon nanotubes had occurred. For the fractured carbon nanotube shown in Figure $2 \mathrm{~b}$, it was impossible for this fractured nanotube to have formed during the CVD process. A vibration-induced tensile force along the highly compartmentalized nanotube should have been responsible for the fracture of the nanotube. A weak link between neighboring fractured surfaces in the compartmentalized nanotube suggests some similarity to the fracture of pure singleor multi-walled carbon nanotubes reported in previous works
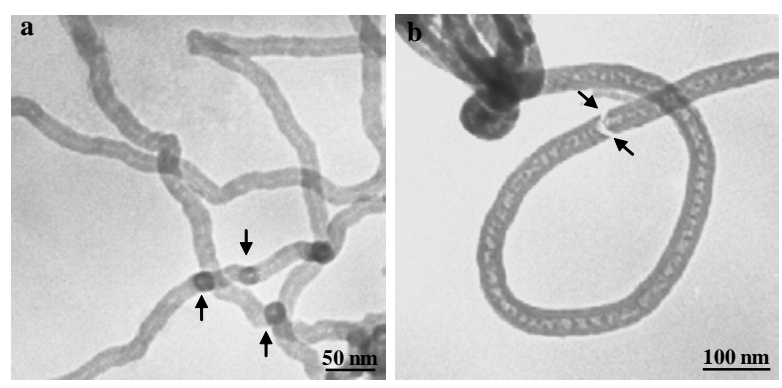

Figure 2: TEM images of carbon nanotubes grown by pyrolyzing acetylene on the Ni-W-P deposited whiskers. (a) Carbon nanotubes with multiple kinks that present circular images (marked by arrows). (b) Stacking cone-related fractur e of the compartmentalized carbon nanotube left with a weak linkage between the separated parts. The arrows point to the fractured surfaces.

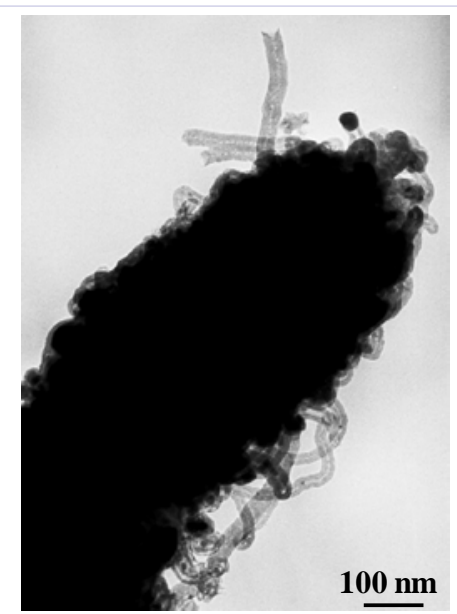

Figure 3: TEM images of carbon nanotubes grown from a Ni-W-P deposited whisker.
$[13,14]$. The failure here should be ascribed as a stacking conerelated fracture since the walls of the two separated parts were self-accommodated. The peculiar physical properties observed with these compartmentalized nanotubes suggest potential properties such as deformation- and kink-related transportation properties $[15,16]$ as well as high-strain-rate deformation ability [17].

During the formation of carbon nanotubes, there occurred complex chemical reactions among the Ni-W-P, SiC and acetylene. Different from the Ni-W-P deposited SiC whiskers (Figure 4a), diffraction peaks corresponding to partially graphitized carbon nanotubes, nickel silicides $\left(\mathrm{Ni}_{31} \mathrm{Si}_{12}\right.$ and $\left.\eta-\mathrm{NiSi}\right)$ and $\mathrm{WC}$ could be observed simultaneously (Figure $4 \mathrm{~b}$ ). It could be inferred that, at elevated temperatures, the $\mathrm{Ni}$ atoms reacted with the $\mathrm{SiC}$ whiskers to form the silicides by following Equation 1. Our heattreatment of the Ni-W-P deposited whiskers in Ar atmosphere did not yield any traces of WC, which verified the findings in other reports that the reaction between $\mathrm{W}$ and $\mathrm{SiC}$ could not occur under temperatures below $800^{\circ} \mathrm{C}[18,19]$. Thus, $\mathrm{C}$ atoms yielded from the reaction of Equation 1 contributed little to the formation of WC. Whereas, activated carbon atoms provided by the pyrolysis of acetylene (Equation 2) were believed to have combined with the $\mathrm{W}$ atoms to form the WC (Equation 3) under a C-rich environment (at $700^{\circ} \mathrm{C}$ ). Considering the reported carburization reaction of $\mathrm{W}$ with methane (at $800^{\circ} \mathrm{C}$ ) to form WC [20], we inferred that the formation of WC during a pyrolysis of acetylene here could be expressed as Equation 4.

$$
\begin{aligned}
& x N i+y S i C=N i x S i y+y C \\
& C_{2} H_{2}\left(g \text { ü̈̈̈̈ } C+H_{2} g\right. \\
& W+C=W C \\
& 2 W+C_{2} H_{2}(g)=2 W C+2 H_{2}(g)
\end{aligned}
$$

HREM analyses of the catalysts encapsulated with asgrown carbon nanostructures indicated that the formation of nickel silicides and WC here had not consumed all of the $\mathrm{Ni}$ and $\mathrm{W}$ elements of the Ni-W-P deposition. Elemental diffusion and separation occurred throughout the pyrolysis reaction. The carbon nanostructures could grow from a Ni nanoparticle (Figure 5), (Ni, P) nanoparticle (Figure 6) and (Ni, W, P) (Figures 7 and 8) nanoparticle. EDS analyses of the composition of the double-element (Ni, P) nanoparticle showed that the contents of elemental $\mathrm{Ni}$ and $\mathrm{P}$ were 70.5 at $\%$ and 29.5 at\%, respectively. The (Ni, P) nanoparticle had a much higher $\mathrm{P}$ content than the original Ni-W-P deposition containing 19.9 at $\%$ of $\mathrm{P}$ element. As a formation of $\mathrm{Ni}_{3} \mathrm{P}$ phase by consuming all of the $\mathrm{Ni}$ element

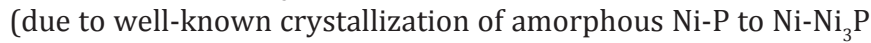
at temperatures above $300^{\circ} \mathrm{C}$ ) in the (Ni, P) particle only needed 23.5 at $\%$ of the $\mathrm{P}$ element, we take the above $(\mathrm{Ni}, \mathrm{P})$ nanoparticle as a composite catalyst which may contain $\mathrm{Ni} \mathrm{Ni}_{3} \mathrm{P}$ and excess $\mathrm{P}$ in the form of either simple substance or phosphide.

For the triple-element $(\mathrm{Ni}, \mathrm{W}, \mathrm{P})$ nanoparticle, the incorporation of carbon atoms in it could only reach a certain 


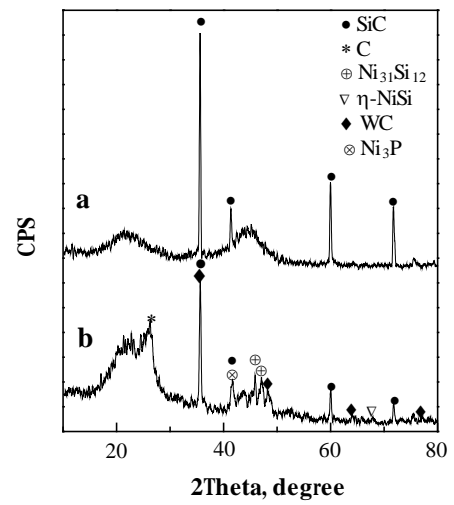

Figure 4: XRD patterns of the (a) Ni-W-P deposited whiskers used for the pyrolysis reaction, and (b) pyrolysis products including nickel silicides and WC.

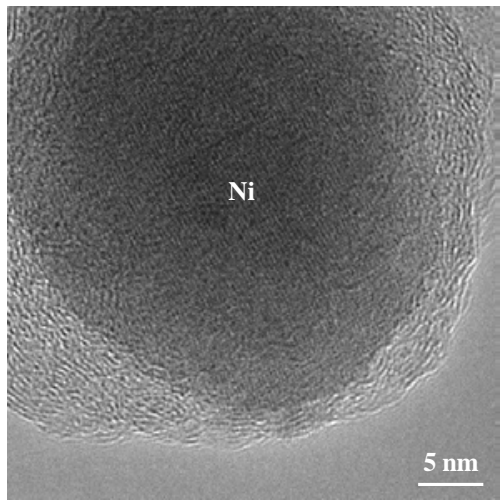

Figure 5: HREM image of the tip of a carbon nanotube with encapsulated Ni nanoparticle.

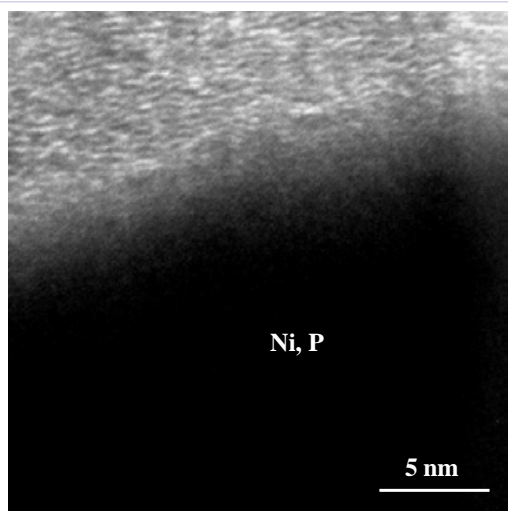

Figure 6: HREM image of non-graphitic structures grown from a $(\mathrm{Ni}$, P) nanoparticle.

level. The carbon nanostructures formed from this nanoparticle consisted of two regions, amorphous or nongraphitic layers at the outer surface and graphitic layers neighboring to the (Ni, W, P) nanoparticle (Figure 7). It could be found that there was no trace of elemental $\mathrm{Ni}, \mathrm{W}$ and $\mathrm{P}$ detected in the graphitic and amorphous layers (Figure 8), which suggests a different catalysis mechanism from that of the double-element $(\mathrm{Ni}, \mathrm{P})$ nanoparticle.

As a candidate material for micro or nano-electronics, the nickel silicide formed at the $\mathrm{Ni}-\mathrm{SiC}$ interface could provide lowresistivity metal contact and interconnect [21-23] between the semiconducting $\mathrm{SiC}$ whisker and the carbon nanotube. The contact or interconnect quality here should be further investigated by adjusting the reaction temperature and time, the yield of the silicides and the quantity of residual catalysts at the connecting areas. In addition to the diffusion of elemental $\mathrm{Ni}, \mathrm{W}$ and P away from the whisker, our HREM observations indicated

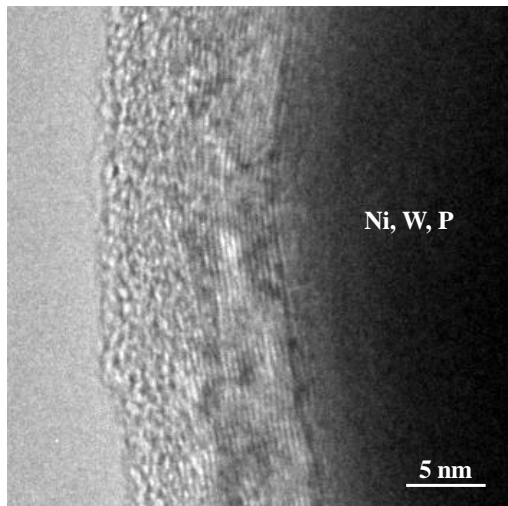

Figure 7: HREM image of nongraphitic/graphitic layers grown from a $(\mathrm{Ni}, \mathrm{W}, \mathrm{P})$ nanoparticle.
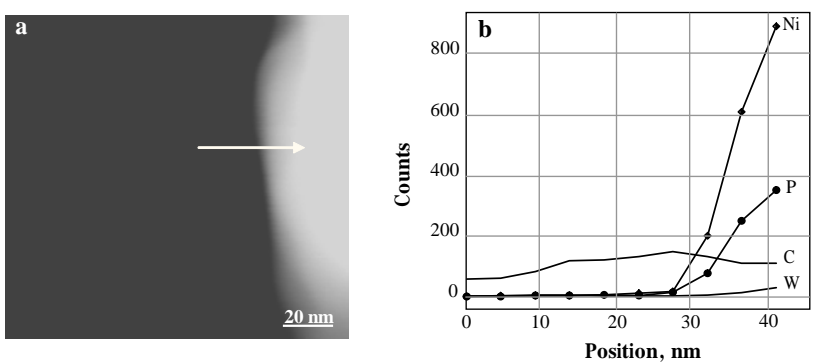

Figure 8: (a) Dark-field TEM image of the (Ni, W, P) nanoparticle coated with pyrolytic carbon shown in Figure 7. (b) EDS patterns showing the distribution of elemental $\mathrm{Ni}, \mathrm{W}, \mathrm{P}$ and $\mathrm{C}$ within the range from the amorphous layer to the $(\mathrm{Ni}, \mathrm{W}, \mathrm{P})$ nanoparticle.
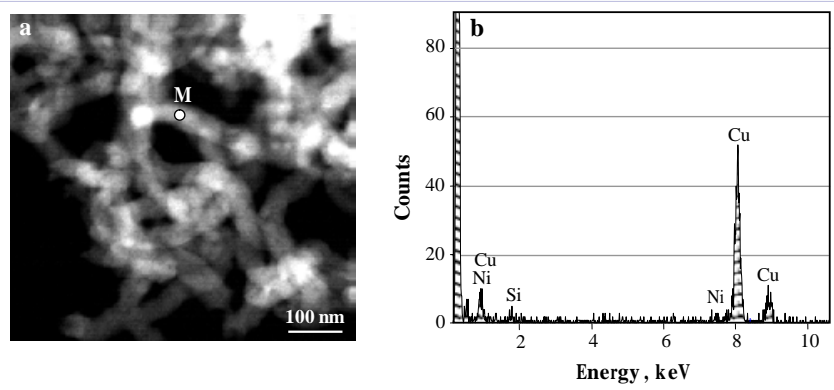

Figure 9: (a) Dark-field TEM image of carbon nanotubes and (b) EDS pattern showing the doping of nickel silicides at point M marked in (a). Cu element detected here was from copper grid used for supporting the carbon nanotubes. 
that a few of the nickel silicides could also diffuse, (presumably with the Ni-based catalyst particles) away from the whisker surfaces and dope in the as-grown carbon nanotubes (Figure 9).

\section{Conclusions}

Carbon nanotubes were grown with the SiC-supported Ni-W-P nanoislands as the catalysts. The compartmentalized nanotubes could fracture with a stacking cone-related mode. The pyrolysis reaction could provide activated carbon atoms and thus result in a C-rich atmosphere favorable for the formation of WC. Carbon nanostructures were found to grow from nanoparticles made up of either single element (Ni) or multiple elements (Ni-P, Ni-W-P). The findings here should contribute to an establishment of multielement catalysis mechanism when various alloy catalysts are involved in a pyolysis reaction, and the fabrication of ideal lowdimensional heterostructures for favorable nanodevices.

\section{References}

1. Wei, B.Q., Vajtai, R., Jung, Y., Ward, J., Zhang, R., Ramanath, G., et al. (2003). Assembly of highly organized carbon nanotube architectures by chemical vapor deposition. Chemistry of Materials, 15(8), 1598-1606.

2. Willems, I., Konya, Z., Colomer, J.F., Van Tendeloo, G., Nagaraju, N., Fonseca, A., et al. (2000). Control of the outer diameter of thin carbon nanotubes synthesized by catalytic decomposition of hydrocarbons. Chemical Physics Letters, 317(1-2), 71-76.

3. Chiang, I.W., Brinson, B.E., Smalley, R.E., Margrave, J.L., \& Hauge, R.H. (2001). Purification and characterization of single-wall carbon nanotubes. The Journal of Physical Chemistry B, 105(6), 1157-1161.

4. Li, Y.M., Kim, W., Zhang, Y.G., Rolandi, M., Wang, D.W., \& Dai, H.J. (2001). Growth of single-walled carbon nanotubes from discrete catalytic nanoparticles of various sizes. The Journal of Physical Chemistry B, 105(46), 11424-11431.

5. Dai, H.J., Rinzler, A.G., Nikolaev, P., Thess, A., Colbert, D.T., \& Smalley, R.E. (1996). Single-wall nanotubes produced by metal-catalyzed disproportionation of carbon monoxide. Chemical Physics Letters, $260(3-4), 471-475$.

6. Cheung, C.L., Kurtz, A., Park, H., \& Lieber, C.M. (2002). Diametercontrolled synthesis of carbon nanotubes. Journal of Physical Chemistry B, 106(10), 2429-2433.

7. Marton, J.P., \& Schlesinger, M. (1968). The nucleation, growth, and structure of thin Ni-P films. Journal of The Electrochemical Society, 115(1), 16-21.

8. Yu, H.S., Sun, X., Luo, S.F., Wang, Y.R., \& Wu, Z.Q. (2002). Applied Surface Science, 191(1-4), 123-127.

9. Hu, J., Ouyang, M., Yang. P., \& Lieber, C.M. (1999). Controlled growth and electrical properties of heterojunctions of carbon nanotubes and silicon nanowires. Nature, 399, 48-51.

10.Zhang, Y., Ichihashi, T., Landree, E., Nihey, F., \& Iijima, S. (1999). Heterostructures of single-walled carbon nanotubes and carbide nanorods. Science, 285, 1719-1722.

11.Valova, E., Armyanov, S., Franquet, A., Hubin, A., Steenhaut, O., Delplancke, J.-L., et al. (2001). Electroless deposited Ni-Re-P, Ni-W-P and Ni-Re-W-P alloys. Journal of Applied Electrochemistry, 31(12), 1367-1372.
12. Tsai, Y., Wu, F., Chen, Y., Peng, P., Duh, J., \& Tsai, S. (2001). Thermal stability and mechanical properties of Ni-W-P electroless deposits. Surface and Coatings Technology, 146-147, 502-507.

13.Wagner, H.D., Lourie, O., Feldman, Y., \& Tenne, R. (1998). Stressinduced fragmentation of multiwall carbon nanotubes in a polymer matrix. Applied Physics Letters, 72(2), 188.

14. Troiani, H.E., Miki-Yoshida, M., Camacho-Bragado, G.A., Marques, M.A.L., Rubio, A., Ascencio, J. A., et al. (2003). Direct observation of the mechanical properties of single-walled carbon nanotubes and their junctions at the atomic level. Nano Letters, 3(6), 751-755.

15. Suenaga, K., Colliex, C., \& Iijima, S. (2001). In situ electron energyloss spectroscopy on carbon nanotubes during deformation. Applied Physics Letters, 78(1), 70.

16. Bozovic, D., Bockrath, M., Hafner, J.H., Lieber, C.M., \& Park, H. (2001). Electronic properties of mechanically induced kinks in single-walled carbon nanotubes. Applied Physics Letters, 78(23), 3693.

17. Yakobson, B.I., Campbell, M.P., Brabec, C.J., \& Bernholc, J. (1997). High strain rate fracture and $\mathrm{C}$-chain unraveling in carbon nanotubes. Computational Materials Science, 8(4), 341-348.

18. Geib, K.M., Wilson, C., Long, R. G., \& Wilmsen, C.W. (1990). Reaction between $\mathrm{SiC}$ and $\mathrm{W}, \mathrm{Mo}$, and $\mathrm{Ta}$ at elevated temperatures. Journal of Applied Physics, 68(6), 2796.

19. Baud, L., Jaussaud, C., Madar, R., Bernard, C., Chen, J.S., \& Nicolet, M.A. (1995). Interfacial reactions of $W$ thin film on single-crystal (001) $\beta$-SiC. Materials Science and Engineering: B, 29(1-3), 126-130.

20. Koc, R., \& Kodambaka, S.K. (2000). Tungsten carbide (WC) synthesis from novel precursors. Journal of the European Ceramic Society, 20(11), 1859-1869.

21.Han, S.Y., Kim, K.H., Kim, J.K., Jang, H.W., \& Lee, K.H. (2001). Ohmic contact formation mechanism of $\mathrm{Ni}$ on $n$-type $4 \mathrm{H}-\mathrm{SiC}$. Applied Physics Letters, 79, 1816.

22. Tinani, M., Mueller, A., Gao, Y., Irene, E.A., Hu, Y.Z., \& Tay, S.P. (2001) In situ real-time studies of nickel silicide phase formation. Journal of Vacuum Science \& Technology B, 19, 376.

23. Deng, F., Johnson, R.A., Asbeck, P.M., Lau, S.S., Dubbelday, W.B., Hsiao, T., et al. (1997). Salicidation process using NiSi and its device application. Journal of Applied Physics, 81, 8047. 